\title{
Simultaneous biogas and biogas slurry production from co-digestion of pig manure and corn straw: Performance optimization and microbial community shift
}

Ning, Jing; Zhou, Mingdian; Pan, Xiaofang; Li, Chunxing; Lv, Nan; Wang, Tao; Cai, Guanjing; Wang, Ruming; Li, Junjie; Zhu, Gefu

Published in:

Bioresource Technology

Link to article, DOI:

10.1016/j.biortech.2019.02.122

Publication date:

2019

Document Version

Peer reviewed version

Link back to DTU Orbit

Citation $(A P A)$ :

Ning, J., Zhou, M., Pan, X., Li, C., Lv, N., Wang, T., Cai, G., Wang, R., Li, J., \& Zhu, G. (2019). Simultaneous biogas and biogas slurry production from co-digestion of pig manure and corn straw: Performance optimization and microbial community shift. Bioresource Technology, 282, 37-47.

https://doi.org/10.1016/j.biortech.2019.02.122

\section{General rights}

Copyright and moral rights for the publications made accessible in the public portal are retained by the authors and/or other copyright owners and it is a condition of accessing publications that users recognise and abide by the legal requirements associated with these rights.

- Users may download and print one copy of any publication from the public portal for the purpose of private study or research.

- You may not further distribute the material or use it for any profit-making activity or commercial gain

- You may freely distribute the URL identifying the publication in the public portal 
1 Simultaneous biogas and biogas slurry production from co-digestion of pig manure and corn straw: performance optimization and microbial community shift

3 Jing Ning,b, Mingdian Zhou ${ }^{\mathrm{a}, \mathrm{b}}$, Xiaofang Pan ${ }^{\mathrm{a}}$, Chunxing Lic, Nan Lv ${ }^{\mathrm{a}, \mathrm{b}}$, Tao Wang ${ }^{\mathrm{a}, \mathrm{b}}$, Guanjing Cai ${ }^{a}$, Ruming Wanga,b, Junjie Li ${ }^{a, b}$, Gefu Zhu ${ }^{a^{*}}$

$6 \quad{ }^{a}$ Key Laboratory of Urban Pollutant Conversion, Institute of Urban Environment, Chinese

7 Academy of Sciences, Xiamen 361021, China

$8 \quad{ }^{b}$ University of Chinese Academy of Sciences, Beijing 100049, China

$9 \quad{ }^{c}$ Department of Environmental Engineering, Technical University of Denmark, DK-2800

10 Lyngby, Denmark

*Corresponding author.

E-mail: gfzhu@iue.ac.cn; Phone: 86-592-6190790; Fax: 86-592-6190790 
12 Abstract: Anaerobic co-digestion (AcoD) is proved as an effective approach to solving a bottleneck problem of the low biogas yield in agricultural biomass waste treatment with anaerobic digestion (AD) technology. The present study investigated the effect of $\mathrm{C} / \mathrm{N}$ radio, organic loading rate (OLR) and total solids (TS) contents on reactor performance in AcoD of pig manure and corn straw for simultaneous biogas and biogas slurry production. It was found that the highest biogas production was obtained at $\mathrm{C} / \mathrm{N}$ ratio of 25 , while the best biogas slurry performance was achieved at $\mathrm{C} / \mathrm{N}$ ratio of 35 . And high OLR and TS resulted in good performances in both biogas production and biogas slurry. At last, the microbial community analysis suggested that Bacteroidetes played a significant role in AcoD process. Acetoclastic methanogenesis was the main pathway for methane production in the stable system. And changing operational parameters could transform and shift the microbial community.

Keywords: Agricultural biomass waste; Anaerobic co-digestion; Biogas; Biogas slurry; Microbial community shift.

\section{Introduction}

With the development of agricultural economy, a large amount of agricultural biomass waste is produced, and now the annual output of livestock manure and crop straw (two major types of agricultural biomass waste) are 1.04 and 3.80 billion tons, respectively, in China. Nowadays, many environmental problems, such as deterioration of water quality,

31 odor problem and eutrophication, have been occurred due to the irrational utilization of wastes (Nasir et al., 2012). So, it is necessary to suitably utilize the agricultural waste, 
which can reduce pollution and alleviate global resource shortage. At present, there are several common agricultural biomass waste treatment methods including composting, making building materials and producing chemicals (like ethanol, ethylene, acrylic acid) (Debertoldi et al., 1983; Sawatdeenarunat et al., 2016). However, there were many problems occurred during applying these methods for disposal of biomass waste, like secondary pollution, insufficient utilization and difficulties in operation and management (Onwosi et al., 2017). Thus, it is necessary and urgent to seek appropriate technology to well make use of agricultural biomass waste.

Anaerobic digestion (AD) has the dual advantage in pollution control and resource recovery. The organic pollutants can be degraded through the metabolism of anaerobic microorganisms to solve environmental pollution problems. In addition, the produced biogas can be applied as clean renewable energy, and biogas slurry containing abundant nutrients including nitrogen, phosphorus and potassium, owned huge potential for liquid fertilizer preparation (Sawatdeenarunat et al., 2015). And up to now, the AD technology has been widely applied in many countries for waste treatment (Akhiar et al., 2017).

In terms of agricultural biomass waste treatment with $\mathrm{AD}$ technology, there is a bottleneck problem of the low biogas yield, which is mainly led by the imbalance of carbon to nitrogen ratio $(\mathrm{C} / \mathrm{N})$. It was reported that the optimum $\mathrm{C} / \mathrm{N}$ ratio value ranged from 20 to 30 in $\mathrm{AD}$ process (Sawatdeenarunat et al., 2015). As the crop straw containing high content of lignocellulose with a relative high $\mathrm{C} / \mathrm{N}$ ratio, it can easily cause the accumulation of volatile fatty acids (VFAs) when utilized as sole substrate in AD process. 
And livestock manure has a lower $\mathrm{C} / \mathrm{N}$ ratio due to its high protein content. The accumulation of ammonia can inhibit the growth of methanogenic microorganisms (Chen et al., 2008). According to the above two problems, researchers tried to balance $\mathrm{C} / \mathrm{N}$ ratio of substrates via anaerobic co-digestion (AcoD) for the agricultural biomass waste treatment to obtain better performance. Lehtomäki et al. (2007) found that the volumetric methane production increased by $65 \%, 58 \%$ and $16 \%$ in manure AcoD with sugar beet tops, grass and straw, respectively. Zhao et al. (2018) reported that the cumulative methane yield in AcoD of cow manure and oat straw was $26.64 \%$ higher than that of oat straw alone. In recent years, the research mainly focused on the effect of operation parameters on biogas production, such as $\mathrm{C} / \mathrm{N}$ ratio, organic loading rate (OLR), total solids (TS) contents and so on. Aboudid et al. (2016) found that specific methane production reached the highest value at $\mathrm{C} / \mathrm{N}$ ratio of 23.5: 1 in AcoD of sugar beet byproduct and cow manure. Li et al. (2015b) reported the maximum biogas production rate was obtained at OLR of $6 \mathrm{~g}$ $\mathrm{VS} \cdot \mathrm{L}^{-1} \cdot \mathrm{d}^{-1}$ in AcoD of rice straw and cow manure. However, most of these studies were conducted in batch experiment, little work was investigated on semi-continuous or continuous reactor operation, which had higher guidance for the practical project. And also, many researchers paid much attention to the impact of TS on AD process, while only a few articles studied its effect on AcoD of livestock manure and crop straw. In terms of another important product of biogas slurry obtained from AD process, the nutrient concentration in biogas slurry is generally too low to be utilized as fertilizer directly (Fan et al., 2014; Li et al., 2013). And technology of concentration and nutrient 
recovery, such as ammonia stripping, ion exchange and vacuum evaporation, are commonly applied to improve the fertilizer efficiency of biogas slurry (Li et al., 2016). But these techniques are difficult to be widely applied due to the high expensive capital expenditure. Therefore, maximizing nutrient concentration of biogas slurry should be considered in AcoD to make full use of resources. So far, there is no literature on this subject. Furthermore, if high biogas yield and high nutrient concentration (N, P and K) from biogas slurry can be simultaneously achieved during AcoD, it will construct an efficient process for sufficient resource utilization of agricultural biomass waste. Based on the above, this study constructed a simultaneous biogas and biogas slurry production process from AcoD of livestock manure and crop straw. The effect of different operational parameters of $\mathrm{C} / \mathrm{N}$ ratio, OLR and TS on biogas production and nutrient concentration of biogas slurry were studied in semi-continuous experiment to optimize the operational process. Moreover, the characteristics of the microbial community structure involved in the AcoD were revealed by high-throughput $16 \mathrm{~S}$ rRNA pyrosequencing. All in all, this study provided detailed technical parameters and practical guidance for the exploration of highly efficient technology for simultaneous production of biogas and biogas slurry from agricultural biomass waste.

\section{Material and methods}

\subsection{Substrates and inoculum}

The basic characteristics of the substrates and inoculum were shown in Table 1. The inoculum was obtained from an internal circulation anaerobic reactor (IC) which used food 
starch as feedstock under mesophilic condition $\left(37 \pm 1^{\circ} \mathrm{C}\right)$. Prior to use, the inoculum was acclimated using glucose at $37^{\circ} \mathrm{C}$ for 1 week. The pig manure was collected from a pig farm of Lesen Ecological Co. Ltd in Xiang'an city, Fujian province, China. The sample was stored at $-18{ }^{\circ} \mathrm{C}$ for use. It was diluted to desired feeding TS concentration and blended in a high-speed blender before inoculation. The corn straw was obtained from Chenghua Abrasive Co. Ltd in Jimei city, Fujian province, China, with particle size less than $1 \mathrm{~mm}$. To improve its digestion efficiency, the corn straw was pretreated as its high lignocellulosic content was difficult to be decomposed and utilized by microorganism (Zheng et al., 2014; Kumar et al., 2009). In this experiment, $\mathrm{NaOH}$ was used to pretreat the corn straw in a glass bottle with a rubber stopper (Chandra et al., 2012). The corn straw was soaked in $5 \% \mathrm{NaOH}$ solution $(\mathrm{g} \mathrm{NaOH} / \mathrm{g}$ TS) with a solid to liquid ratio of 1: 10 (g: $\mathrm{ml}$ ) at ambient temperature for 5 days and manually mixed twice a day. After pretreatment, the corn straw was washed to neutral with deionized water for seal storage before dried in vacuum drier at $60{ }^{\circ} \mathrm{C}$.

\subsection{Experimental design}

All the AD experiments were performed in three continuous stirred tank reactors (CSTR) with working volume of $8 \mathrm{~L}$ (Fig. 1). The temperature of the CSTR was maintained at $37 \pm 1^{\circ} \mathrm{C}$ by a hot water jacket system, and stirred by a mechanical agitating equipment at $130 \mathrm{rpm} \cdot \mathrm{min}^{-1}$. The prepared feed was stored in a stirring tank with volume of $5 \mathrm{~L}$, which was controlled at $6^{\circ} \mathrm{C}$ by a water jacket system. The biogas produced were 
collected using the gas bag.

\section{Fig. 1}

In this experiment, the pig manure with OLR of $0.5 \mathrm{~g} \mathrm{VS} \cdot \mathrm{L}^{-1} \cdot \mathrm{d}^{-1}$ and inoculum with $200 \mathrm{~g} \cdot \mathrm{L}^{-1}$ (based on dry matter) were injected into three CSTR reactors (CSTR I, CSTR II and CSTR III). And the OLR was gradually increased to $1,1.5$ and $2 \mathrm{~g} \mathrm{VS} \cdot \mathrm{L}^{-1} \cdot \mathrm{d}^{-1}$ to startup of the reactors, until system reached steady state. CSTR I was applied to investigate the effect of different $\mathrm{C} / \mathrm{N}$ ratios $(13.45,20,25,30,35$ and 300) on AcoD. TS of feed $\underline{\text { substrates and OLR remained constant, which were } 2 \mathrm{~g} \mathrm{VS} \cdot \mathrm{L}^{-1} \cdot \mathrm{d}^{-1} \text { and } 5 \% \text { respectively }}$ throughout the fermentation process. Then, the evaluation of OLR $(2,3,4,5,6$ and $8 \mathrm{~g}$ VS $\left.\cdot \mathrm{L}^{-1} \cdot \mathrm{d}^{-1}\right)$ and TS $(5 \%, 8 \%, 12 \%, 15 \%, 20 \%$ and $25 \%)$ on the performance of AcoD of pig manure and corn straw were conducted in CSTR II and CSTR III applying the optimal $\mathrm{C} / \mathrm{N}$ ratio. TS was maintained at $5 \%$ by shortening hydraulic retention time (HRT) in CSTR II. And TS was gradually increased with a constant OLR $\left(2 \mathrm{~g} \mathrm{VS} \cdot \mathrm{L}^{-1} \cdot \mathrm{d}^{-1}\right)$ in CSTR III. Table 2 shows the operating parameters in all systems under various conditions. Composition and volume of the biogas and nutrient concentration of biogas slurry including total nitrogen (TN), total phosphorus (TP) and total potassium (TK) were analyzed to evaluate the efficiency of AD.

\section{Table 2}

\subsection{Analytical methods}

The alkalinity, $\mathrm{pH}$, concentration of total ammonia nitrogen (TAN) and TN, TS and VS were determined according to Standard Methods (APHA, 2012). C, N and C/N ratio 
were analyzed by elemental analyzer (Vario Macro CHNS-O-/CL, Elementar, Germany).

139 Samples were centrifuged at $12,000 \mathrm{r} \cdot \mathrm{min}^{-1}$ for $4 \mathrm{~min}$. And the supernatant was acidized to

$140 \mathrm{pH}<2$ using $3 \mathrm{~mol} \cdot \mathrm{L}^{-1} \mathrm{HCl}$ and filtered through a $0.22 \mu \mathrm{m}$ membrane for analyzing VFAs

141 including acetic acid, lactic acid, propionic acid, butyric acid, pentanoic acid and formic

142 acid. VFAs were measured by ion chromatography (ICS-3000, Dionex, America) equipped

143 with analytical column $\left(\mathrm{Pac}^{\mathrm{TM}}\right.$ AS11-HC, $\left.4 \times 250 \mathrm{~mm}\right)$ and protect column (Ion $\mathrm{Pac}^{\mathrm{TM}}$

144 AG11-HC, $4 \times 50 \mathrm{~mm})$. The flow phase was $\mathrm{KOH}$ eluent and column temperature was

$14535^{\circ} \mathrm{C}$. Daily accumulative biogas production was collected using the gas bag. The specific

146 biogas production rate (SBP) was calculated according to Eq. (1).

$147 \quad S B P=V_{\text {day }} / V S_{a d d}$

Where $V_{d a y}$ was the daily accumulative biogas production in the reactor, $\mathrm{mL} \cdot \mathrm{d}^{-1} ; V S_{a d d}$ was the daily feed added, $\mathrm{g}$.

Biogas was analyzed using gas chromatography (GC9790 II, Fuli, China), equipped

151 with a thermal conductivity detector TCD with argon as carrier gas. Temperature of

152 thermal conductivity, column and detector were $160^{\circ} \mathrm{C}, 120^{\circ} \mathrm{C}$ and $160{ }^{\circ} \mathrm{C}$, respectively,

153 and the model of packed column was TDX-1 (2 $\mathrm{m}$ long and a $3 \mathrm{~mm}$ inner diameter). TP

154 and TK were measured by inductively coupled plasma - atomic emission spectrometry

155 (Optima 7000DV, PerkinElmer, America).

\section{$156 \quad 2.4$ DNA extraction and pyrosequencing analysis}

157 The digestate samples were collected on the last day of each phase of the reactor to 158 analyze their microbial communities via high-throughput 16S rRNA pyrosequencing. The 
DNA was extracted from three samples from each stage and mixed for the high-throughput

160 16S rRNA pyrosequencing. And then the DNA was extracted by Fast DNA TM SPIN Kit

161 for Soil (MP Biomedicals, USA). The V4 region of 16S rRNA gene was amplified by PCR

162 using the primers 515FmodF (GTGYCAGCMGCCGCGGTAA) and 806RmodR

163 (GGACTACNVGGGTWTCTAAT). Sequencing was performed on an Illumina Hiseq2500

164 PE250 platform accomplished by Novogene (Beijing, China).

\section{Results and discussion}

$166 \quad 3.1$ Effect of $\mathbf{C} / \mathrm{N}$ ratio on production of biogas and biogas slurry

\section{$167 \quad 3.1 .1$ Analysis of the stability of the reactors at various $\mathbf{C} / \mathbf{N}$}

The pig manure with $\mathrm{C} / \mathrm{N}$ ratio of 13.45 was served as sole feedstock during startup

169 period of reactor I. Results showed that $\mathrm{pH}$ was $6.95-7.00$ (Fig. 2a), which located in the

170 optimal range of AD of 6.80 - 7.20 (Hagos et al., 2017). The concentrations of TAN and

171 VFAs were $367.66 \mathrm{mg} \cdot \mathrm{L}^{-1}$ and $11.56 \mathrm{mg} \cdot \mathrm{L}^{-1}$, respectively (Fig. 2a \& 2b), which were

172 lower than the inhibitory concentration during AD process $\left(3860 \mathrm{mg} \cdot \mathrm{L}^{-1}\right.$ and $\left.3000 \mathrm{mg} \cdot \mathrm{L}^{-1}\right)$

173 (Li et al., 2015a; Benabdallah et al., 2009). So, the system had sufficient buffering capacity

174 and operated stably in this stage. Subsequently, pig manure and corn straw were fed with

$175 \mathrm{C} / \mathrm{N}$ ratio of 20 for AcoD. The concentration of TAN reduced gradually at the beginning,

176 and then tended to be a constant of $247.76 \mathrm{mg} \cdot \mathrm{L}^{-1}$ finally. And as $\mathrm{C} / \mathrm{N}$ ratio continues to go

177 up, the concentration of TAN fell and reached a value of $160.71 \mathrm{mg} \cdot \mathrm{L}^{-1}$ at $\mathrm{C} / \mathrm{N}$ ratio of 35

178 (Fig. 2a). This clearly showed that AcoD can prevent the possible adverse effect of high

179 TAN on system stability during AD of pig manure. The change of alkalinity also declined 
181 previous results that alkalinity was mainly provided by TAN and reflected buffer capacity

182 during AD process (Nasir et al., 2012; Benabdallah et al., 2009). The $\mathrm{pH}$ also dropped from

1836.92 to 6.65 which was lower than the optimum range of AD (Fig. 2a). Nevertheless, pH

184 still levelled off at each stage, and no VFAs accumulation occurred (no more than $20 \mathrm{mg} \cdot \mathrm{L}^{-}$

$185^{1}$, Fig. 2a) in the reactor. SBP also indicated that the reactor had normal operation

186 performance (Fig. 3a) at the $\mathrm{C} / \mathrm{N}$ ratio of $20,25,30$ and 35.

187 When pure corn straw $(\mathrm{C} / \mathrm{N}$ ratio $=300)$ was fed in the reactor, TAN concentration

188 and alkalinity significantly decreased and dropped to $52.81 \mathrm{mg} \cdot \mathrm{L}^{-1}$ and $873.37 \mathrm{mg}$

$189 \mathrm{CaCO}_{3} \cdot \mathrm{L}^{-1}$, respectively (Fig. 2a). In AD process, alkalinity of $1000 \mathrm{mg} \mathrm{CaCO} \cdot \mathrm{L}^{-1}$ is

190 needed to resist $\mathrm{CO}_{2}$ and VFAs, so as to maintain $\mathrm{pH}$ level and the stability of system (Ren

191 and Wang, 2004). Due to the low alkalinity, $\mathrm{pH}$ failed to maintain invariable and

192 significantly reduced to 6.18 . VFAs was also accumulated up to $1661.74 \mathrm{mg} \cdot \mathrm{L}^{-1}$, consisting

193 primarily of propionic acid $\left(1601.91 \mathrm{mg} \cdot \mathrm{L}^{-1}\right)$ (Fig. 2b). Reports confirmed that high VFAs

194 concentration can inhibit AD, especially propionic acid (Akhiar et al., 2017; Dang et al.,

195 2016). Wang et al. (2009) explored the effect of different VFAs on AD that the

196 methanogenic microorganisms were inhibited with propionic acid concentration reaching

$197900 \mathrm{mg} \cdot \mathrm{L}^{-1}$. Obviously, propionic acid in this stage significantly exceeded the considered

198 inhibitory concentration. And the ratio of VFAs to alkalinity is used to determine the

199 stability of the AD system (Callaghan et al., 2002). When the value of VFAs/alkalinity is

200 less than 0.4 , the system is considered to be stable (Callaghan et al., 2002). And it is 
unstable with higher than 0.4 . The high VFAs/alkalinity of 1.92 in the reactor demonstrated that the system was unstable, which were consistent with the SBP (Fig. 3a) in AD process with corn straw as sole feedstock.

\subsubsection{Effect of $\mathrm{C} / \mathrm{N}$ ratio on performance of biogas production and biogas slurry}

In addition, the $\mathrm{SBP}$ and $\mathrm{CH}_{4}$ production was tested to characterize the effect of

different $\mathrm{C} / \mathrm{N}$ ratio on the biogas potential. The results meant that it was important to ensure that $\mathrm{C} / \mathrm{N}$ ratio was not too high or too low, as this leaded to a low $\mathrm{SBP}$ and $\mathrm{CH}_{4}$ production in AcoD. The maximum SBP was obtained at $\mathrm{C} / \mathrm{N}$ ratio of 25 with $514.75 \mathrm{~mL} \cdot \mathrm{g}$ $\mathrm{VS}_{\mathrm{add}}{ }^{-1} \cdot \mathrm{d}^{-1}$ on AcoD (Fig. 3a), which was consistent with the optimal C/N ratio mentioned

211 in many literatures (Hagos et al., 2017; Zhang et al., 2016). Li et al. (2015a) reported that

212 the biogas yield from AcoD of pig manure and rice straw reached the highest value at $\mathrm{C} / \mathrm{N}$ 213 ratio of 23.4. With the $\mathrm{C} / \mathrm{N}$ ratio of 20,25 and 30 , the $\mathrm{CH}_{4}$ proportion was $63.28 \%, 62.17 \%$ 214 and $66.08 \%$, respectively (Fig. 3b). The $\mathrm{CH}_{4}$ proportion reduced significantly to $58.35 \%$

215 with $\mathrm{C} / \mathrm{N}$ ratio of 35 . Because methanogenic microorganisms are more sensitive to $\mathrm{pH}$ than 216 acidogenesis microorganisms (Hagos et al., 2017). Growth of methanogenic bacteria

217 slightly reduced at $\mathrm{pH}$ values of 6.65 below 6.80 in this phase. $\mathrm{CH}_{4}$ production was 277.68 , $218320.02,320.70$, and $273.01 \mathrm{~mL} \cdot \mathrm{g} \mathrm{VS}_{\mathrm{add}}{ }^{-1} \cdot \mathrm{d}^{-1}$, respectively, at the four $\mathrm{C} / \mathrm{N}$ ratios (Fig. 3b).

219 Highest $\mathrm{CH}_{4}$ production was obtained at $\mathrm{C} / \mathrm{N}$ ratios of 25 and 30 . Considering SBP and 220 methane content, the AcoD system obtained the optimum biogas production performance 221 at $\mathrm{C} / \mathrm{N}$ ratio of 25. 
$224 \mathrm{CH}_{4}$ also reduced dramatically to $47.35 \%$ and $21.42 \mathrm{~mL} \cdot \mathrm{g} \mathrm{VS}_{\mathrm{add}}{ }^{-1} \cdot \mathrm{d}^{-1}$ due to the accumulation of VFAs (Fig. 3b). Many previous literatures also indicated that the imbalance $\mathrm{C} / \mathrm{N}$ ratio of crop straw could lead to accumulation of VFAs causing lower biogas yield even system collapse (Sawatdeenarunat et al., 2015). Xie et al. (2011) reported that accumulation of VFAs inhibited AD process of single silage straw, and the system eventually failed. The results showed that the AcoD could effectively solve the problem of 230 acid inhibition. Zhao et al. (2018) have also proven that AcoD of straw and nitrogen-rich

231 substrate is beneficial to the stable operation of the reactor. And system with mono-

232 digestion of pig manure was stable and SBP $\left(493.00 \mathrm{~mL} \cdot \mathrm{g} \mathrm{VS}_{\mathrm{add}}{ }^{-1} \cdot \mathrm{d}^{-1}\right)$ was greater than

233 that of AcoD with $\mathrm{C} / \mathrm{N}$ ratios of 20, 30 and 35. Li et al. (2015b) also got the same result in

234 AcoD of rice straw and cow manure. This may be due to the lower biodegradability and

235 bioaccessibility of corn straw compared with pig manure. In AcoD with OLR of $2 \mathrm{~g} \mathrm{VS} \cdot \mathrm{L}^{-}$

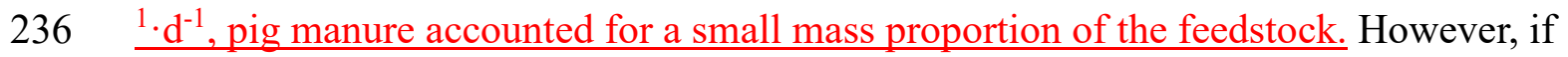

237 mono-digestion of each feedstock of AcoD process was performed individually (Li et al.,

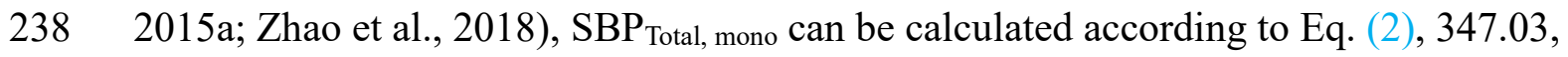

$239284.97,243.41$ and $212.43 \mathrm{~mL} \cdot \mathrm{g} \mathrm{VS}_{\text {add }}{ }^{-1} \cdot \mathrm{d}^{-1}$ respectively. Compared with that, SBP

240 increased by $26.45 \%, 80.63 \%, 99.38 \%$ and $120.25 \%$ respectively in AcoD. It can be seen

241 that the AcoD obviously optimized the biogas production performance of ingredients.

$S B P_{\text {Total }, \text { mono }}=R_{P M} \cdot S B P_{P M, \text { mono }}+R_{C S} \cdot S B P_{C S, \text { mono }}$ 
corn straw at different $\mathrm{C} / \mathrm{N}$ ratio (based on VS).

The results of nutrient concentration in biogas slurry indicated that the concentration

of TK was the highest, followed by TN and TP was the least (Fig. 4a). And similar result

was also reported by previous study (Jin et al., 2011). The total nutrient concentration was

13.45 (pig manure as mono-substrates), 20, 25, 30, 35 and 300 (corn straw as mono-

251 substrates) (Fig. 4a). It was implied that the AcoD significantly enhanced the nutrient

252 concentration (mainly in terms of TK), compared to AD of corn straw. Jin et al. (2011)

253 analyzed the nutrient contents of 16 large-scale biogas project in Jiangsu province, and

254 reported that concentration of TN, TP and TK in biogas slurry of pig farms was in the

255 ranges of $400-900 \mathrm{mg} \cdot \mathrm{L}^{-1}, 30-100 \mathrm{mg} \cdot \mathrm{L}^{-1}$ and $100-500 \mathrm{mg} \cdot \mathrm{L}^{-1}$, respectively, which

256 fitted with the relevant ranges in the present study. The lower concentration of TN and

257 higher concentration of TK in other stages were caused by the reduction of pig manure and 258 the increase of corn straw in the substrate. Total nutrient concentration in the reactor

259 reached the highest value at $\mathrm{C} / \mathrm{N}$ ratio of 35.

260 In general, the AcoD effectively solved the problem of low SBP and biogas slurry

261 nutrients in mono-digestion and maximized the resource utilizing potential of corn straw. 


\subsubsection{Analysis of the stability of the reactors at various OLR}

Organic nitrogen is converted to ammonia which is an essential nutrient substance required for microorganism during $\mathrm{AD}$. With OLR from 2 to $6 \mathrm{VS} \cdot \mathrm{L}^{-1} \cdot \mathrm{d}^{-1}$, TAN gradually

267 reduced from 322.87 to $283.42 \mathrm{mg} \cdot \mathrm{L}^{-1}$ due to the consumption of nitrogen sources by 268 methanogens, and further resulted in decrease in alkalinity from 2637.18 to $2400.97 \mathrm{mg}$

$269 \mathrm{CaCO}_{3} \cdot \mathrm{L}^{-1}$ (Fig. 2c). As the OLR increased, the $\mathrm{pH}$ value edged down to 6.75 from 6.89

270 (Fig. 2c). Many researches have indicated that the increase in OLR could lead to a

271 reduction of $\mathrm{pH}$ value (Sinbuathong et al., 2010). While, the $\mathrm{pH}$ was maintained at the

272 suitable scope for methanogenic microorganism due to good buffering capacity at every

273 stage. VFAs was consumed by syntrophic-methanogenic associations with maximum value

274 of no more than $30 \mathrm{mg} \cdot \mathrm{L}^{-1}$ and no acid inhibition occurred at the OLR of $2-6 \mathrm{~g} \mathrm{VS} \cdot \mathrm{L}^{-1} \cdot \mathrm{d}^{-1}$

275 (Fig. 2d). At the end of the experiment, the AcoD was operated at OLR of $8 \mathrm{~g} \mathrm{VS} \cdot \mathrm{L}^{-1} \cdot \mathrm{d}^{-1}$.

276 During the first five days, TAN, alkalinity and $\mathrm{pH}$ value held constant. While, the sharp

277 decline of $\mathrm{pH}$ to 5.93 after the fifth day was not conducive to the growth of methanogenic

278 microorganism. The VFAs were up to $1423.58 \mathrm{mg} \cdot \mathrm{L}^{-1}$ significantly including propionic

$279 \operatorname{acid}\left(616.17 \mathrm{mg} \cdot \mathrm{L}^{-1}\right)$ and acetic acid $\left(554.10 \mathrm{mg} \cdot \mathrm{L}^{-1}\right)$, which was below the inhibitory

280 concentration. But the VFAs/alkalinity of 0.58 was higher than 0.4 , indicating the unstable

281 of the system. This was also corresponded to low SBP observed at the OLR of $8 \mathrm{~g} \mathrm{VS} \cdot \mathrm{L}^{-}$

$282{ }^{1} \cdot \mathrm{d}^{-1}$ (Fig. 3c). Obviously, VFAs/alkalinity is more reasonable as an indicator of system

283 stability, compared with VFAs concentration. 


\subsubsection{Effect of OLR on performance of biogas production and biogas slurry}

The SBP and $\mathrm{CH}_{4}$ production in the CSTR reactor under different OLRs are listed in

Fig. 3c and Fig. 3d, respectively. In this study, it was obviously observed that SBP and $\mathrm{CH}_{4}$ production from AcoD declined with OLR increased from 2 to $3 \mathrm{~g} \mathrm{VS} \cdot \mathrm{L}^{-1} \cdot \mathrm{d}^{-1}$. While, they gradually increased after OLR going up to $5 \mathrm{~g} \mathrm{VS} \cdot \mathrm{L}^{-1} \cdot \mathrm{d}^{-1}$. It might due to that microorganisms obtained a higher ability of resist impact load after operating in increasing OLR system for a long time. The highest $\mathrm{SBP}$ and $\mathrm{CH}_{4}$ production were achieved at OLR of $2 \mathrm{~g} \mathrm{VS} \cdot \mathrm{L}^{-1} \cdot \mathrm{d}^{-1}$ with 499.00 and $281.84 \mathrm{~mL} \cdot \mathrm{g} \mathrm{VS}_{\mathrm{add}}{ }^{-1} \cdot \mathrm{d}^{-1}$. Comino et al. (2010) found that the optimal OLR was $5.15 \mathrm{~g} \mathrm{VS} \cdot \mathrm{L}^{-1} \cdot \mathrm{d}^{-1}$ with highest SBP of $477.2 \mathrm{~mL} \cdot \mathrm{g} \mathrm{VS}_{\text {add }}{ }^{-1} \cdot \mathrm{d}^{-1}$ in AcoD system of cow manure and energy crops. Kaoutar et al. (2015) reported that SBP reached the maximum in AcoD of sugar beet byproduct and pig manure with OLR of $4.2 \mathrm{~g}$ $\mathrm{VS} \cdot \mathrm{L}^{-1} \cdot \mathrm{d}^{-1}$. Nevertheless, Li et al. (2015a) reported that there was no impact on biogas production with OLR of $3-8 \mathrm{~g} \mathrm{VS} \cdot \mathrm{L}^{-1} \cdot \mathrm{d}^{-1}$ in the AcoD of pig manure and rice straw. These 297 indicated that the optimal OLR was different in various anaerobic systems. As OLR went 298 from 2 to $6 \mathrm{~g} \mathrm{VS} \cdot \mathrm{L}^{-1} \cdot \mathrm{d}^{-1}$, volumetric biogas production rate (VBPR) significantly 299 increased, which were $1.00,1.31,1.83,2.29$ and $2.61 \mathrm{~L} \cdot \mathrm{L}_{\text {reactor volume }}{ }^{-1} \cdot \mathrm{d}^{-1}$, respectively 300 (Fig. 3c). VBPR is an indicator of the efficiency of the reactor. High VBPR improves the 301 volume utilization of the reactor and reduces the operating cost, which is of great 302 significance in practical engineering ( $\mathrm{Li}$ et al., 2015a). It was obviously observed that SBP 303 reached the maximum at low OLR, while high VBPR was obtained at high OLR. However, $304 \mathrm{SBP}$ and $\mathrm{CH}_{4}$ production reduce under high OLR of $6 \mathrm{~g} \mathrm{VS} \cdot \mathrm{L}^{-1} \cdot \mathrm{d}^{-1}$. And when it further 
raised to $8 \mathrm{~g} \mathrm{VS} \cdot \mathrm{L}^{-1} \cdot \mathrm{d}^{-1}$, AcoD was inhibited with significantly decrease in SBP and VBPR.

306 Because the growth of methanogens was inhibited by the high VFAs concentration resulted

307 from the metabolic imbalance between acidogenesis microorganisms and methanogens (Ye

308 et al., 2013). On the other hand, the short HTR caused a large loss of microorganisms at

309 high OLR. Meanwhile, the slow growth and reproduction of methanogens was not

310 conducive to timely supplement of microorganisms, which leads to the decline of the

311 digestive capacity in the system. Previous studies also suggested that the system would

312 deteriorate at excessive OLR in AD process. Kaoutar et al. (2015) and Li et al. (2015a)

313 found that the system was inhibited at OLR of $12 \mathrm{~g} \mathrm{VS} \cdot \mathrm{L}^{-1} \cdot \mathrm{d}^{-1}$. Chen et al. (2016) said that

314 reactor could be operated stably when the OLR was lower than $1.8 \mathrm{~g} \mathrm{VS} \cdot \mathrm{L}^{-1} \cdot \mathrm{d}^{-1}$. This may

315 be due to the difference of substrates and reactors in AD.

316 Total nutrient concentration increased first and then decreased with obtaining the

317 highest value of $974.30 \mathrm{mg} \cdot \mathrm{L}^{-1}$ at OLR of $5 \mathrm{~g} \mathrm{VS} \cdot \mathrm{L}^{-1} \cdot \mathrm{d}^{-1}$ (Fig. 4b). It was mainly

318 contributed by the increase in TN concentration. TK concentration fluctuated a little and

319 TP concentration fell slightly as OLR elevated. It was conducive to the improvement of

320 total nutrient concentration in biogas slurry with OLR lower than $5 \mathrm{~g} \mathrm{VS} \cdot \mathrm{L}^{-1} \cdot \mathrm{d}^{-1}$. But the

321 high OLR had negative effect on the production of total nutrient concentration of biogas

322 slurry. Considering the biogas production and biogas slurry nutrients, the OLR of $5 \mathrm{~g}$

$323 \mathrm{VS} \cdot \mathrm{L}^{-1} \cdot \mathrm{d}^{-1}$ could be a better operating parameter for better performance in $\mathrm{SBP}, \mathrm{CH}_{4}$

324 production and total nutrient concentration. 


\subsubsection{Analysis of the stability of the reactors at various TS}

The performance of AcoD of pig manure and corn straw was investigated at different

TS of $5 \%, 8 \%, 12 \%, 15 \%, 20 \%$ and $25 \%$, respectively. TAN raised from 269.59 to 396.69

$\mathrm{mg} \cdot \mathrm{L}^{-1}$ along with TS gradually increasing from $5 \%$ to $15 \%$ (Fig. 2e). However, as TS

338 So, the alkalinity in the system was suitable for AD process. With the increase of TS from $5 \%$ to $20 \%$, the $\mathrm{pH}$ value stabilized at $6.90-7.00$ (Fig. 2e). And when TS raised to $25 \%$,

340 the $\mathrm{pH}$ reduced gradually to 6.70 and remained steady due to good buffering capacity. And

341 total VFAs concentration was kept at a low level, with a maximum of $20 \mathrm{mg} \cdot \mathrm{L}^{-1}$ in this

342 system (Fig. 2f). Obviously, there was no accumulation of VFAs and TAN with increasing 343 TS from $5 \%$ to $25 \%$ in this system. Riya et al. (2018) reported that VFAs accumulation 344 was observed in reactor with TS more than $28 \%$. In this experiment, the $\mathrm{pH}$ presented a 345 marked decline and $\mathrm{CH}_{4}$ proportion also declined significantly at TS of $25 \%$ (Fig. $3 \mathrm{f}$ ). 
346 Further research is needed on whether $\mathrm{pH}$ will further reduce and VFAs accumulate with

347 the continuous increase of TS.

\section{3.3.2 Effect of TS on performance of biogas production and biogas slurry}

349 TS of substance is another important factor effecting biogas production during AD

350 process. The results of this study showed that the SBP were 499.23, 435.54, 482.11,

$351538.33,549.82$ and $461.43 \mathrm{~mL} \cdot \mathrm{g} \mathrm{VS}_{\text {add }}{ }^{-1} \cdot \mathrm{d}^{-1}$ (Fig. 3e) with TS of 5\%, 8\%, 12\%, 15\%, 20\%

352 and $25 \%$, respectively. As TS raised from $8 \%$ to $20 \%$, SBP and $\mathrm{CH}_{4}$ proportion gradually

353 increased (Fig. 3e\&3f). While, SBP and $\mathrm{CH}_{4}$ proportion fell immediately when TS was

$35425 \%$. Previous studied also revealed that $\mathrm{CH}_{4}$ production was inhibited at high TS levels

355 (Fan et al., 2014). Study suggested that the reduction of $\mathrm{CH}_{4}$ production was possibly due

356 to mass transfer limitation caused by the decrease of free water at high TS (Abbassi-

357 Guendouz et al. 2012). Li et al. (2013) reported that $\mathrm{CH}_{4}$ yield declined on AcoD of corn

358 stover and chicken manure with TS range of 5.1\%-22.4\%. But in these studies, the change

359 in TS accompanied a change in OLR. In batch experiments, a few papers investigated the

360 effect of variable TS on $\mathrm{CH}_{4}$ production with a constant OLR and obtained the same

361 phenomenon with this experiment. An et al. (2017) found $\mathrm{CH}_{4}$ production increased firstly

362 and then declined at TS of $2 \%, 4 \%, 6 \%, 8 \%$ and $10 \%$ in batch mesophilic AD. While there

363 is no literature so far focusing on the effect of TS on $\mathrm{CH}_{4}$ production in semi - continuous

364 mesophilic AD. Xu et al. (2014) proposed a mass diffusion-caused hydrolysis inhibition

365 mechanism to explain the phenomenon. And they revealed that there was a TS threshold

366 between $15 \%$ and $20 \%$ for $\mathrm{AD}$ of lignocellulosic biomass. When TS is lower than the 

exceeding this threshold. It could be saw that TS threshold was around $20 \%$ in this experiment. And the highest SBP and $\mathrm{CH}_{4}$ production were observed at TS of $20 \%$.

Total nutrient concentration in biogas slurry increased significantly as TS raised (Fig. 4c).

373 When TS was $25 \%$, the total nutrient concentration was about three times of that in TS of

$3745 \%$. This was because the reduction of water content resulted in the concentration of

375 nutrients in biogas slurry as TS went up. Obviously, compared with $\mathrm{C} / \mathrm{N}$ ratio and OLR, TS

376 had a relatively significant influence on total nutrient concentration. AcoD with high TS

377 not only improved the production of biogas, but also obtained biogas slurry with high

378 nutrient concentration. It was also suggested from the experiment that the high TS

379 substrate reduced the addition of additional water during AcoD and lowed the volume of

380 the biogas slurry.

In summary, it can be observed that the high SBP and high nutrient concentration $(\mathrm{N}$,

$382 \mathrm{P}$ and $\mathrm{K}$ ) from biogas slurry are not necessarily obtained simultaneously in AcoD system

383 with different $\mathrm{C} / \mathrm{N}$, OLR and TS. Therefore, in practical engineering, the selection of

384 operating parameters can be determined according to the economic calculation. In addition,

385 it is unilateral to evaluate the properties of biogas slurry only considering nutrient

386 concentration of $\mathrm{N}, \mathrm{P}$ and $\mathrm{K}$. In order to obtain more comprehensive information about

387 biogas slurry, some plant hormones, including indoleacetic acid, abscisic acid and 
gibberellin, and safety indexes, such as antibiotics and heavy metals, are also required to

389 be determined. Although the concentrations of indoleacetic acid, abscisic acid and

390 gibberellin were detected in this study, the values were quite low (no data showed).

\subsection{Microbiological analysis during biogas and biogas slurry co-production process}

\subsubsection{Dynamics of microbial community richness and diversity}

The microbial diversity parameters, including Shannon, Simpson, Ace and Chao 1,

were estimated at different stages of the reaction systems (Table 3). It could be observed

that community diversity and population richness showed a decrease trend with increase of

$396 \mathrm{C} / \mathrm{N}$ ratio and OLR in stable phases of AcoD system. This could be explained by an

397 increase in the relative abundance of microorganisms which performed major functions in

398 the system (Fig. 6). Interestingly, when the system was in disorder (at $\mathrm{C} / \mathrm{N}$ ratio of 300 and

399 OLR of $\left.8 \mathrm{~g} \mathrm{VS} \cdot \mathrm{L}^{-1} \cdot \mathrm{d}^{-1}\right)$, the diversity index plummeted. This suggested that community

400 diversity in stable phase was significantly greater than that in deteriorative phase. The

401 diversity indexes may be considered as indicators of process stability. While, Li et al.

402 (2015) reported that the diversity indexes of both bacteria and archaea had no significant

403 differences between stable and deteriorative phases in AD of food waste. This could be

404 explained by the difference of other factors such as substrate in AD process. And it also

405 was found that the diversity indexes had no significant differences between $5 \%$ and $8 \%$ at

406 low TS. At TS of $12 \%, 15 \%$ and $20 \%$, the same phenomenon was observed and the

407 diversity index significantly dropped compared to that at low TS. A significant decrease

408 was observed when TS continued to be up to $25 \%$. It indicated that the microbial 


\subsubsection{Dynamics of bacterial populations at the phylum and genus level}

For the bacterial community, the most abundant bacterial population phyla were

414 all AcoD reactors (Fig. 5). The phylum Bacteroidetes was the dominant and the second predominant phylum was Firmicutes in AcoD of pig manure and corn straw process.

416 However, many studies indicated that the Firmicutes predominated in AD or co-digestion

417 of agricultural waste (Jiménez et al. 2016). Only Jiménez et al. (2016) investigated AcoD

418 of pig manure and rice straw using clay as additive, and reported that Bacteroidetes was

419 the dominant microorganisms in $\mathrm{AD}$. When corn straw $(\mathrm{C} / \mathrm{N}$ ratio $=300)$ as mono-

420 substrates was digested, the relative abundance of Firmicutes increased obviously, which

421 became the dominant microorganism in this stage. Zheng et al. (2015) also found that

422 Firmicutes had a higher relative abundance during the AD of switchgrass alone in

423 comparison with AcoD. This could be explained by the tolerance of Firmicutes with low

$424 \mathrm{pH}$ (Zheng et al. 2015). At this stage, VFAs accumulation occurred and the $\mathrm{pH}$ went down

425 significantly. In addition, it might also be resulted from the composition of substrate.

426 Firmicutes is cellulose-degrading bacteria and have been reported as the dominant

427 community in digester of lignocellulosic biomass in many papers (Xu et al. 2018). With the

428 increase of TS, Bacteroidetes was gradually enriched and the relative abundance of

429 Firmicutes dropped. Until TS was up to $25 \%$, the relative abundance of Bacteroidetes had 
430 a slight decrease. This was consistent with previous studies. Yi et al. (2014) also found the

431 Bacteroidetes was enriched in the reactor with the increase of TS from $5 \%$ to $20 \%$ in the

432 AD of food waste. And it was seen that the relative abundance of Bacteroidetes and

433 Firmicutes was bound to change in the reverse direction when the operating parameter

434 changed. Researchers had reported that there was strong negative correlation of the relative

435 abundance between Bacteroides and Firmicutes (Chen et al. 2016). Studies have noted that

436 the ratio of Firmicutes to Bacteroidetes (F/B) might have potential utility as an indicator of

437 process stability, and dropped significantly during process disturbance and rebounded after

438 process recovery (Chen et al. 2016). This finding was in agreement with the F/B variation

439 in the system operated by different OLR, while F/B increased sharply when the system was

440 disrupted in system of $\mathrm{C} / \mathrm{N}$ with 300 . Therefore, the rationality of $\mathrm{F} / \mathrm{B}$ as an indicator of

441 process stability of AD remains to be verified.

\section{Fig. 5}

443 On the level of genus, Rikenellaceae belonging to Bacteroidetes played an important

444 role in in all AcoD reactors (Fig. 6). With increase of $\mathrm{C} / \mathrm{N}$ ratio and TS, the relative

445 abundance of Rikenellaceae was on the rise. Rikenellaceae was observed to be

446 predominant and also showed an increase trend with the elevating of TS in other anaerobic

447 digesters (Yi et al. 2014). Rikenellaceae had a very small fluctuation at OLR of 2 - $6 \mathrm{~g}$

$448 \mathrm{VS} \cdot \mathrm{L}^{-1} \cdot \mathrm{d}^{-1}$ (Fig. 6c). While, it was dramatically enriched when OLR was up to $8 \mathrm{~g} \mathrm{VS} \cdot \mathrm{L}^{-}$

$449{ }^{1} \cdot \mathrm{d}^{-1}$, which was corresponded to the increase of acetic acid and propionic acid in reactor,

450 since the main end-products of Rikenellaceae fermentation were acetic acid and propionic 
acid (Yi et al. 2014). In addition, it could be observed that Roseimarinus belonging to Bacteroides remained at a level of relative abundance with $5.76 \%$, which might due to the reactor had a $\mathrm{pH}$ of 5.93. Roseimarinus was observed to grow at $\mathrm{pH} 6.00-8.50$ with optimum growth at pH $7.50-8.00$ (Liu et al. 1999). Bacteroidetes (relative abundance of $13.70 \%$ ) as the main genera in Bacteroidetes, can ferment carbohydrates, including glucose, to product of acid (mainly acetic and succinic acids) in the AD of corn straw (Fig. 6a). Compared to AcoD at different $\mathrm{C} / \mathrm{N}$ ratios, Acetivibrio, Turicibacter, Clostridiales,

Saccharofermentans and Ruminococcaceae belonging to Firmicutes were significantly $6.53 \%, 6.43 \%, 5.62 \%$ and $4.03 \%$ in relative abundance respectively. They could improve

461 the production of short-chain fatty acids, among which Ruminococcaceae had a great 462 capacity on cellulose and hemicellulose degradation of corn straw (Yi et al. 2014). As 463 mentioned above, VFAs concentration in the reactor was relatively high at this stage,

464 mainly propionic acid. Consistent with that, a lower proportion of Smithella (relative 465 abundance of $0.65 \%$ ), a propionate-oxidizing bacterium, could be observed (Rosenberg et 466 al. 2014). Conversely, propionic acid was not the main acid of VFAs unlike corn straw as 467 mono-substrates for AD at OLR of $8 \mathrm{~g} \mathrm{VS} \cdot \mathrm{L}^{-1} \cdot \mathrm{d}^{-1}$. Similarly, Smithella had high relative 468 abundance.

\subsubsection{Dynamics of methanogens populations at the genus level}

471 Considering the methanogens, Methanosaeta which use only acetate to produce 
methane, had been dominant genus in all stable systems, indicating that acetoclastic methanogenesis played important roles in $\mathrm{CH}_{4}$ production (Fig. 6). The relative abundance of dominant methanogens did not fluctuate at $\mathrm{C} / \mathrm{N}$ ratio of 20, 25 and 30. Along with the $\mathrm{C} / \mathrm{N}$ ratio increased to 35, the relative abundance of Methanosaeta went up. However, whether this was caused by the increase of $\mathrm{C} / \mathrm{N}$ ratio still needs to be further investigation. With the increase of TS, the contribution of Methanosaeta was gradually enriched from $65.71 \%$ to $83.74 \%$. And with the change of OLR, the relative abundance of Methanosaeta reduced at first and then increased. Methanosaeta accounted for more than $70 \%$ in relative abundance with OLR was 5 and $6 \mathrm{~g} \mathrm{VS} \cdot \mathrm{L}^{-1} \cdot \mathrm{d}^{-1}$ (Fig. 6d). However, when OLR was $8 \mathrm{~g}$ $\mathrm{VS} \cdot \mathrm{L}^{-1} \cdot \mathrm{d}^{-1}$, Methanoregula became the dominant methanogens accounting for $60.44 \%$, indicating that the dominant methanogenesis pathway shifted from acetoclastic methanogenesis to hydrogenotrophic methanogenesis. Some studies also observed hydrogenotrophic methanogens became more dominant in AD system under higher OLR condition (Ros et al. 2017). This was because that hydrogenotrophic methanogens have better tolerance to the environment, especially for low $\mathrm{pH}$ condition (Ros et al. 2017). Although high VFAs was accumulated during AD of corn straw, the dominant methanogenesis pathway was still acetoclastic methanogenesis. This might be due to the substrate composition was different between reactor I and II. The most abundant hydrogenotrophic methanogens were Methanobacterium, Methanospirillum and Methanobrevibacter in all stable systems (Fig. 6). Obviously, OLR had great influence on relative abundance of Methanobacterium. In general, the microbial community in AcoD 
494 and reactor performance.

\section{Conclusions}

In this study, the optimal engineering parameters were obtained through investigating the effects of $\mathrm{C} / \mathrm{N}$ ratio, OLR and TS on performance of biogas and biogas slurry from AcoD of pig manure and corn straw. It was found that the high SBP and high nutrient concentration from biogas slurry are not necessarily obtained simultaneously in AcoD. In

500 practical engineering, the selection of process parameters can be determined according to

501 the project requirement. The microbial community analysis indicated that the diversity and 502 structure of microbial community were closely related to the operation parameters, which 503 affect the operation state of the reactor.

\section{Acknowledgement}

505 The authors would like to thank the National Key Research and Development Program of

506 China (Contract No.2017YFD0800804-03), the National Natural Science Foundation of

507 China (Contract No. 21477122, 51678553, 21276248, 51808525, 21876167), the Project of 508 the Natural Science Foundation of Fujian Province (Contract No.2016J01273, 509 2017J05092), the Xiamen Science and Technology Project (Contract No.

510 3502Z20182003), IUE CAS Young Talents Frontier Project (Contract No.IUEQN201501)

511 and FY2015 Japanese-China Research Cooperative Program (Contract

512 No.2016YFE0118000) for their supports for this study. 


\section{References}

514 Abbassi-Guendouz A., Brockmann D., Trably E., Dumas C., Delgenès J.P., Steyer J.P., Escudié R., 2012. Total solids content drives high solid anaerobic digestion via mass transfer limitation. Bioresour. Technol. 111, 55-61.

Aboudi K., Alvarez-Gallego C.J., Romero-Garcia L.I., 2016. Evaluation of methane generation and process stability from anaerobic co-digestion of sugar beet byproduct and cow manure. J. Biosci. Bioeng. 121 (5), 566-572.

Akhiar A., Battimelli A., Torrijos M., Helene C., 2017. Comprehensive characterization of the liquid fraction of digestates from full-scale anaerobic co-digestion. Waste Manag.

An D., Wang T.F., Zhou Q., Wang C.S., Yang Q.Y., Xu B.J., Zhang Q.F., 2017. Effects of total solids content on performance of sludge mesophilic anaerobic digestion and dewaterability of digested sludge. Waste Manag. 62, 188-193.

APHA, 2012. Standard Methods for the Examination of Water and Wastewater, 22th ed. American Public Health Association, DC, USA.

Benabdallah E.H.T., Astals S., Galí A., Mace S., Mata-Alvarez J., 2009. Ammonia influence in anaerobic digestion of OFMSW. Water Sci. Technol. 59 (6), 1153-1158.

Callaghan F.J., Wase D.A.J., Thayanithy K., Forster C.F., 2002. Continuous co-digestion of cattle slurry with fruit and vegetable wastes and chicken manure. Biomass Bioenergy.

533 Chandra R., Takeuchi H., Hasegawa T., Kumar R., 2012. Improving biodegradability and 
biogas production of wheat straw substrates using sodium hydroxide and hydrothermal pretreatments. Energy. 43, 273-282.

Chen S., Cheng H.C., Wyckoff K.N., He Q., 2016. Linkages of Firmicutes and Bacteroidetes populations to methanogenic process performance. J. Ind. Microbiol. Biotechnol. 43 (6), 771-781.

Chen Y., Cheng J.J., Creamer K.S., 2008. Inhibition of anaerobic digestion process: a review. Bioresour. Technol. 99, 4044-4064.

Comino E., Rosso M., Riggio V., 2010. Investigation of increasing organic loading rate in

Dang Y., Holmes D.E., Zhao Z.Q., Woodard T.L., Zhang Y.B., Sun D.Z., Wang L.Y., Nevin the co-digestion of energy crops and cow manure mix. Bioresour. Technol. 101 (9), 3013-3019.

Debertoldi M., Vallini G., Pera K.A., 1983. The biology of composting: A review. Waste Manage. Res. 1 (1), 157-176.

Fan M., Zhu H.G., Ma J.Q., 2014. Measurement and analysis of biogas fertilizer use K.P., Lovley D.R., 2016. Enhancing anaerobic digestion of complex organic waste with carbon-based conductive materials. Bioresour. Technol. 220, 516-522.

\section{2}

Hagos K., Zong J.P., Li D.X., Liu C., Lu X.H., 2017. Anaerobic co-digestion process for biogas production: Progress, challenges and perspectives. Renew. Sustainable Energy Rev. 76, 1485-1496. 
Jimenez J., Theuerl S., Bergmann I., Klocke M., Guerra G., Romero-Romero O., 2016. Prokaryote community dynamics in anaerobic co-digestion of swine manure, rice straw and industrial clay residuals. Water Sci. Technol. 74 (4), 824-835.

Jin H.M., Chang Z.Z., Ye X.M., Yan M., Jin Z., 2011. Physical and chemical characteristics of anaerobically digested slurry from large-scale biogas project in Jiangsu Province. Trans. Chin. Soc. Agric. Eng. 27 (1), 291-296.

Kaoutar A., Carlos J., Luis I., 2015. Semi-continuous anaerobic co-digestion of sugar beet byproduct and pig manure: effect of the organic loading rate (OLR) on process performance. Bioresour. Technol. 194, 283-290.

Kumar P., Diane M.B., Michael J.D., Stroeve P., 2019. Methods for Pretreatment of Lignocellulosic Biomass for Efficient Hydrolysis and Biofuel Production. Ind. Eng. Chem. Res. 48 (8), 3713-3729.

Lehtomäki, A., Huttunen S., Rintala J.A., 2007. Laboratory investigations on co-digestion of energy crops and crop residues with cow manure for methane production: Effect of crop to manure ratio. Resour. Conserv. Recycl. 51 (3), 591-609.

Li D, Liu S.C., Mi L., Li Z.D., Yuan Y.X., Yan Z.Y., Liu X.F., 2015a. Effects of feedstock ratio and organic loading rate on the anaerobic mesophilic co-digestion of rice straw and pig manure. Bioresour. Technol. 187, 120-127.

Li D., Liu S.C., Mi L., Li Z.D., Yuan Y.X., Yan Z.X., Liu X.F., 2015b. Effects of feedstock ratio and organic loading rate on the anaerobic mesophilic co-digestion of rice straw and cow manure. Bioresour. Technol. 189, 319-326. 
Li L., He Q., Ma Y., Wang X.M., Peng X.Y., 2015. Dynamics of microbial community in a mesophilic anaerobic digester treating food waste: Relationship between community structure and process stability. Bioresour. Technol. 189, 113-120.

Li X., Guo J.B., Dong R.J., Ahring B.K., Zhang W.Q., 2016. Properties of plant nutrient: Comparison of two nutrient recovery techniques using liquid fraction of digestate from anaerobic digester treating pig manure. Sci. Total Environ. 544, 774-781.

Li Y.Q., Zhang R.H., Chen C., Liu G.Q., He Y.F., Liu X.Y., 2013. Biogas production from co-digestion of corn stover and chicken manure under anaerobic wet, hemi-solid, and solid state conditions. Bioresour. Technol. 149 (4), 406-412.

Liu Y.T., Balkwill D.L., Aldrich H.C., Drake G.R., Boone D.R., 1999. Characterization of the anaerobic propionate-degrading syntrophs Smithella propionica gen. nov. sp. nov. and Syntrophobacter wolinii. Int. J. Syst. Bacteriol. 49 (2), 545-556.

Nasir I.M., Ghazi T.I.M., Omar R., 2012. Anaerobic digestion technology in livestock manure treatment for biogas production: A review. Eng. Life Sci. 12 (3), 258-269.

Onwosi C.O., Igbokwe V.C., Odimba J.N., Eke I.E., Nwankwoala M.O., Iroh I.N., Ezeogu L.I., 2017. Composting technology in waste stabilization: On the methods, challenges and future prospects. J. Environ. Manag. 190, 140-157.

Ren N.Q., Wang A.J., 2004. The method and technology of anaerobic digestion. Chem. ind. Press. 30-31.

Riya S., Suzuki K., Meng L., et al, 2018. The influence of the total solid content on the stability of dry-thermophilic anaerobic digestion of rice straw and pig manure. Waste 
Ros M., de Souza Oliveira Filho J., Perez Murcia M.D., Bustamante M.A., Moral R., Coll digestion of pig slurry and fruit and vegetable waste: Dissection of the microbial community structure. J. Cleaner Prod. 156, 757-765.

Rosenberg E., DeLong E.F., Lory S., Stackebrandt E., Thompson F., 2014. The

Sawatdeenarunat C., Surendra K.C., Takara D., Oechsner H., Khanal S.K., 2015. Bi Anaerobic digestion of lignocellulosic biomass: challenges and opportunities. Bioresour. Technol. 178, 178-186.

Sawatdeenarunat, C., Nguyen, D., Surendra, K.C., Shrestha, S., Rajendran, K., Oechsner, opportunities. Bioresour. Technol. 215, 304-313.

Sinbuathong N., Sillapacharoenkul B., Khun-Anake R., Watts D., 2010. Optimum organic loading rate for semi-continuous operation of an anaerobic process for biogas production from Jatropha curcas seed cake. Int. J. Glob. Warm. 2 (2), 179-188. concentrations on methane yield and methanogenic bacteria. Biomass Bioenergy. 33 (5), 848-853. ratio on methane production in batch anaerobic co-digestion of concentrated pig 
manure and grass silage. Bioresour. Technol. 102 (10), 5728-5733.

619 Xu F.Q., Wang Z.W., Tang L., Li Y.B., 2014. A mass diffusion-based interpretation of the 620 effect of total solids content on solid-state anaerobic digestion of cellulosic biomass. Bioresour. Technol. 167 (3), 178-185.

Xu R., Zhang K., Liu P., Khana A., Xiongc J., Tianc F., Li X.K., 2018. A critical review on the interaction of substrate nutrient balance and microbial community structure and function in anaerobic co-digestion. Bioresour. Technol. 247, 1119-1127.

Ye J.Q., Li D., Sun Y.M., Wang H.G., Yuan Z.H., Zheng F., Wang Y., 2013. Improved biogas production from rice straw by co-digestion with kitchen waste and pig manure. Waste Manag. 33, 2653-2658.

Yi J., Dong B., Jin J.W., Dai X.H., 2014. Effect of Increasing Total Solids Contents on Anaerobic Digestion of Food Waste under Mesophilic Conditions: Performance and from sorghum stem by co-digestion with cow manure. Int. J. Hydrogen Energy. 41,

Zhao Y.B., Sun F.R., Yu J.D., Cai, Y.F., Luo, X.S., Cui, Z.J., Hu Y.G., Wang, X.F., 2018. Co-digestion of oat straw and cow manure during anaerobic digestion: Stimulative and inhibitory effects on fermentation. Bioresour. Technol. 269, 143-152. waste activated sludge and wheat straw through ratio optimization and ferroferric 
640 Zheng Y., Zhao J., Xu F.Q., Li Y.B., 2014. Pretreatment of lignocellulosic biomass for 641 enhanced biogas production. Prog. Energy Combust. Sci. 42, 35-53.

642 Zheng Z.H., Liu J.H., Yuan X.F., Wang X.F., Zhu W.B., Yang F.Y., Cui Z.J., 2015. Effect of 643 dairy manure to switchgrass co-digestion ratio on methane production and the 644 bacterial community in batch anaerobic digestion. Appl. Energy. 151, 249-257. 645 


\section{Figure Captions}

647 Fig. 1 Experimental apparatus for anaerobic digestion.

648 Fig. 2 Reactor performance on all digestion: (a) $\mathrm{pH}$, Alkalinity and TAN at various $\mathrm{C} / \mathrm{N}$

649 ratio, (b) VFA at various $\mathrm{C} / \mathrm{N}$ ratio, (c) $\mathrm{pH}$, Alkalinity and TAN at various OLR, (d) VFA at

650 various OLR (e) $\mathrm{pH}$, Alkalinity and TAN at various TS, (f) VFA at various TS.

651 Fig. 3 Reactor biogas performance on all digestion: (a) SBR at various $\mathrm{C} / \mathrm{N}$ ratio, (b) $\mathrm{CH}_{4}$

652 proportion and $\mathrm{CH}_{4}$ production at various $\mathrm{C} / \mathrm{N}$ ratio, (c) $\mathrm{SBR}$ at various $\mathrm{OLR}$, (d) $\mathrm{CH}_{4}$

653 proportion and $\mathrm{CH}_{4}$ production at various OLR (e) SBR at various TS, (f) $\mathrm{CH}_{4}$ proportion

654 and $\mathrm{CH}_{4}$ production at various $\mathrm{TS}$.

655 Fig. 4 Reactor biogas slurry performance on all digestion: (a) at various $\mathrm{C} / \mathrm{N}$ ratio, (b) at

656 various OLR, (c) at various TS.

657 Fig. 5 Taxonomic compositions in each sample at the phylum level of bacteria (a) at

658 various $\mathrm{C} / \mathrm{N}$ ratio, (b) at various $\mathrm{OLR},(\mathrm{c})$ at various $\mathrm{TS}$.

659 Fig. 6 Taxonomic compositions in each sample at the genus level of bacteria and

660 methanogens (a) bacteria at various $\mathrm{C} / \mathrm{N}$ ratio, (b) methanogens at various $\mathrm{C} / \mathrm{N}$ ratio, (c)

661 bacteria various OLR, (d) methanogens at various OLR, (e) bacteria at various TS, (f)

662 methanogens at various TS.

663 


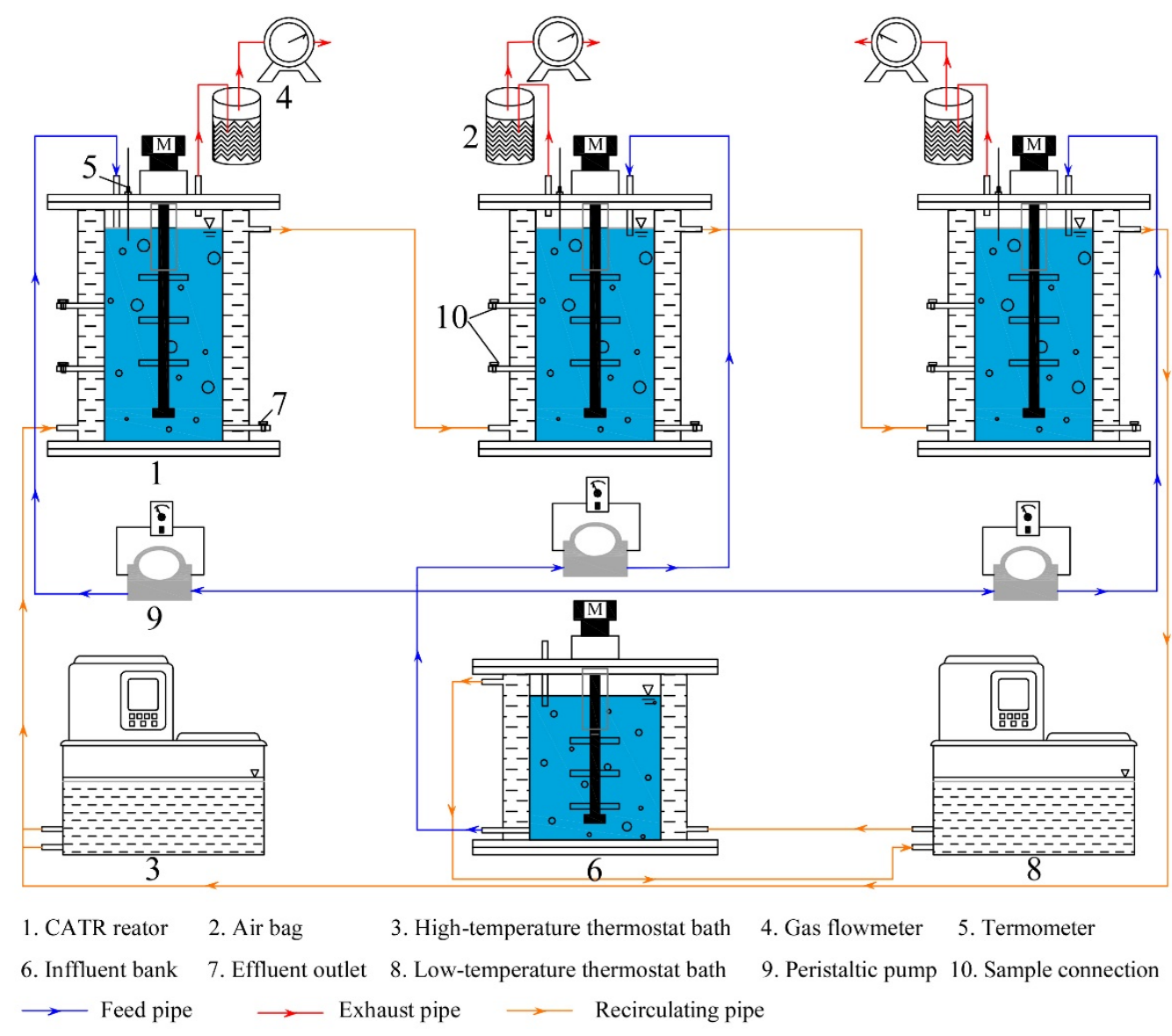

665

Fig. 1

666 
(a)

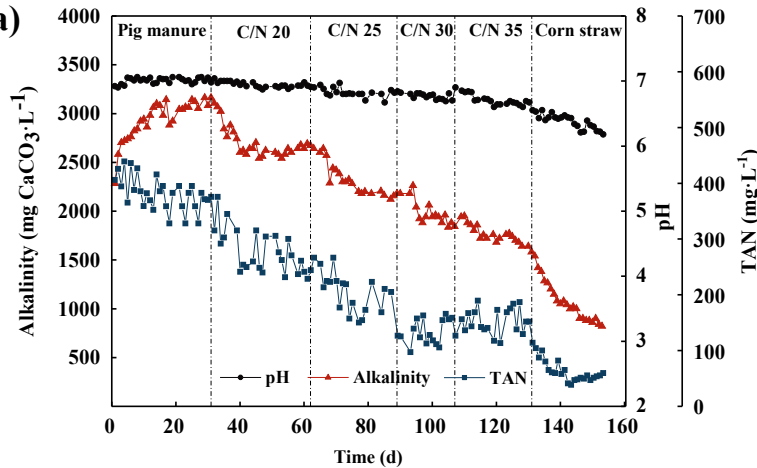

(c)

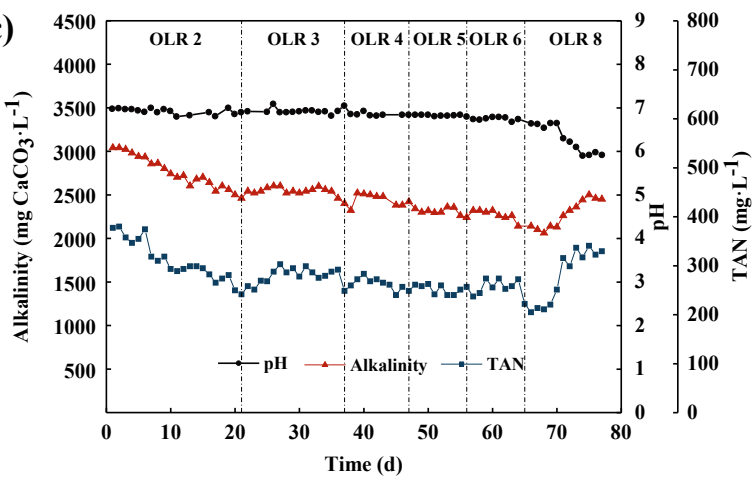

668

669

(e)

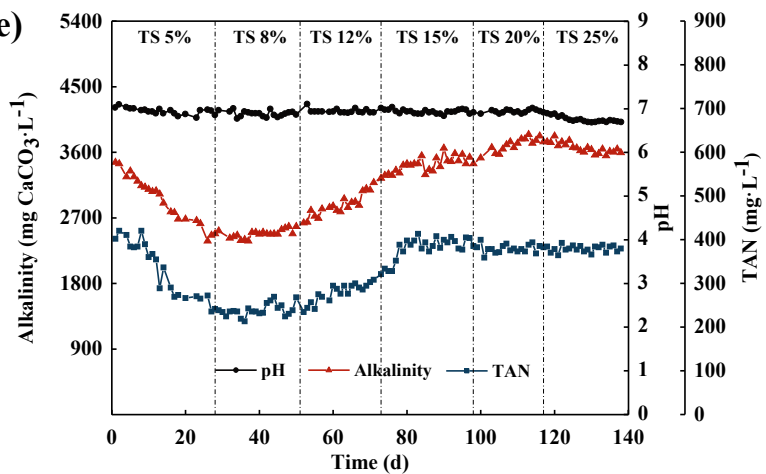

(b)

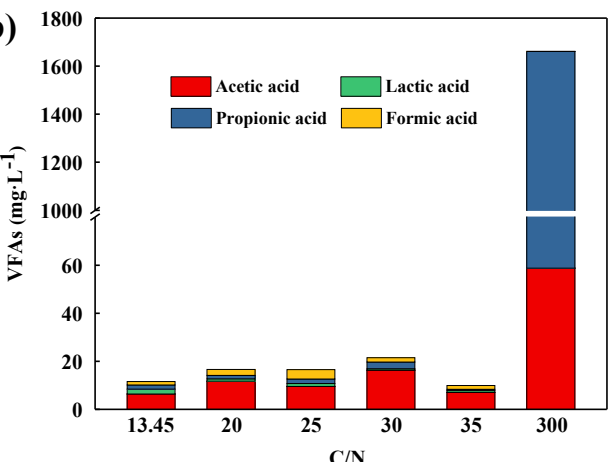

(d)

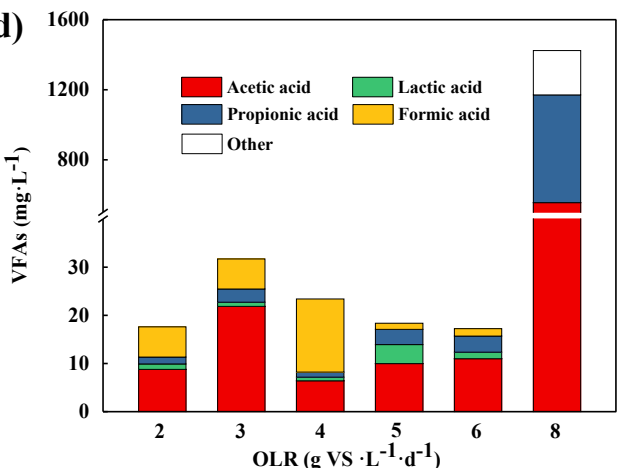

(f)



Fig. 2 
(a)

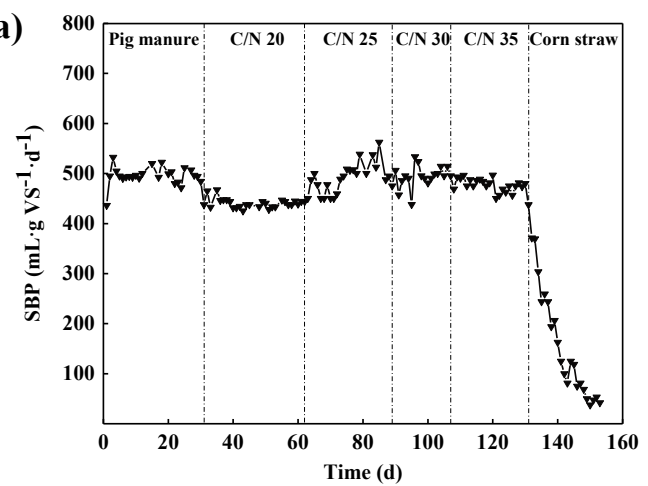

672

673

674

(c)

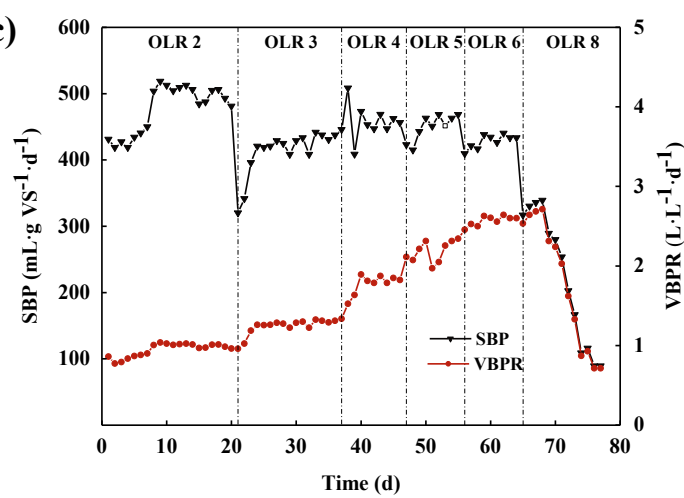

(e)

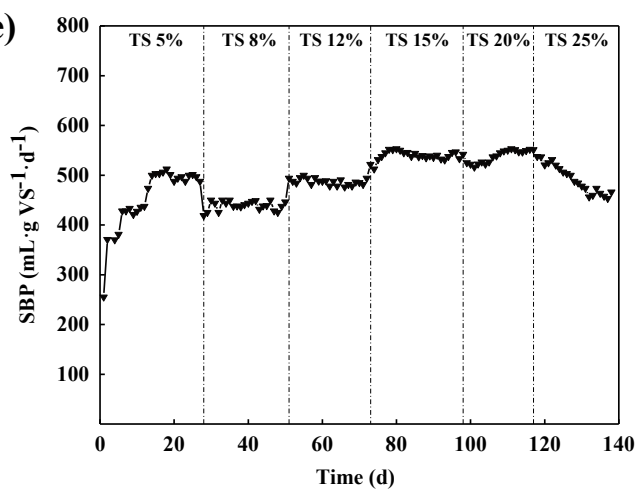

675

676

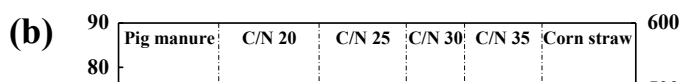

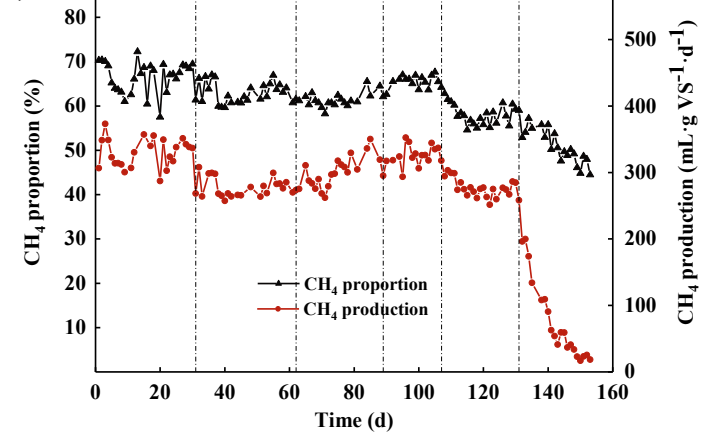

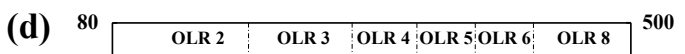

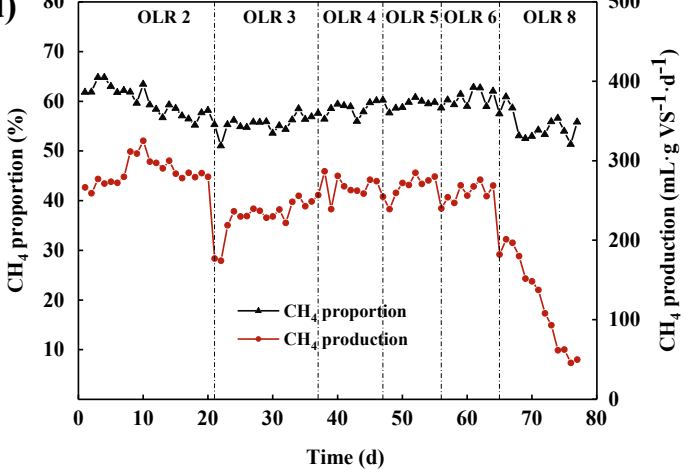

(f) \begin{tabular}{ll|l|l|l|l|l|l|l|}
80 & & & \\
\cline { 2 - 4 } & TS 5\% & TS 8\% & TS 12\% & TS 15\% & TS 20\% & TS 25\% & 600 \\
\hline
\end{tabular}

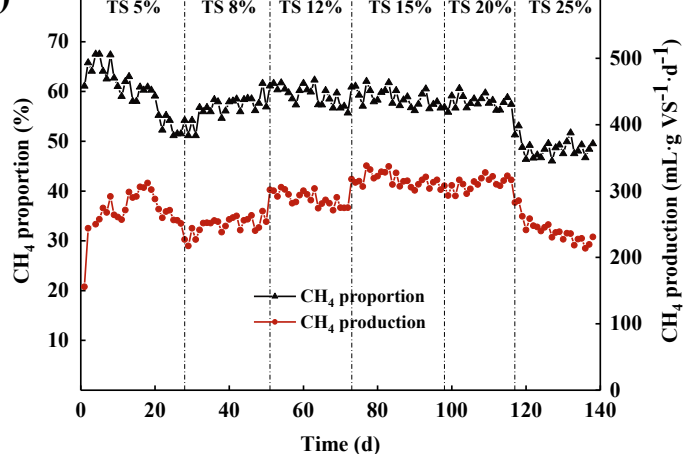

Fig. 3 

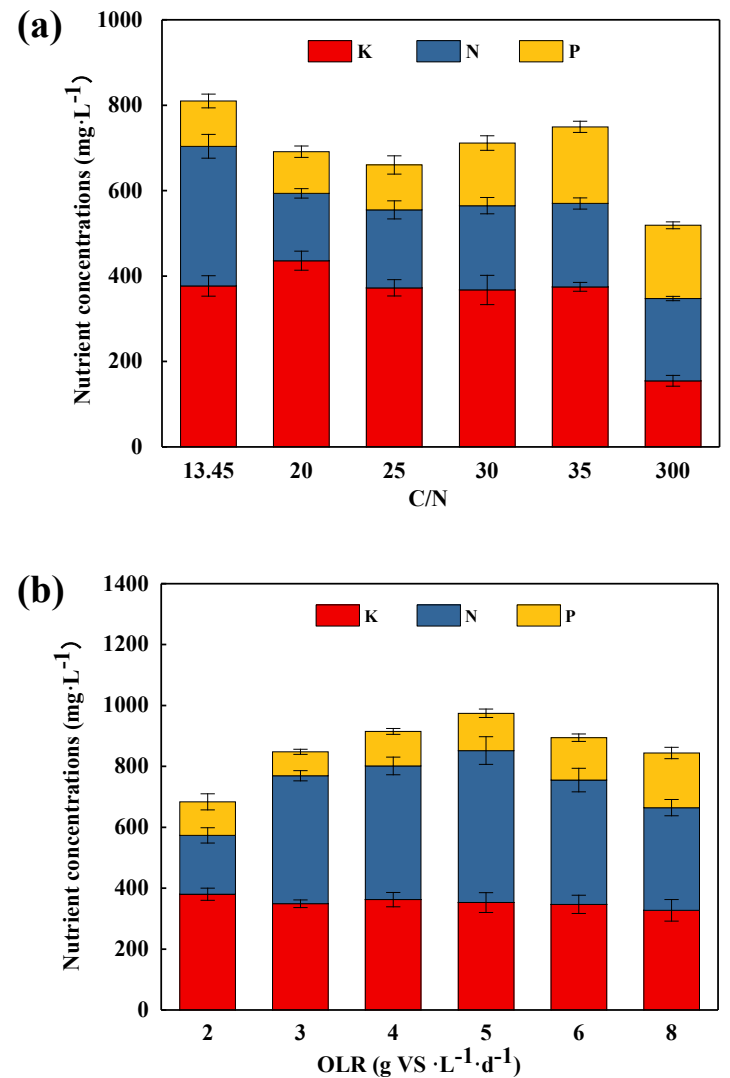

678

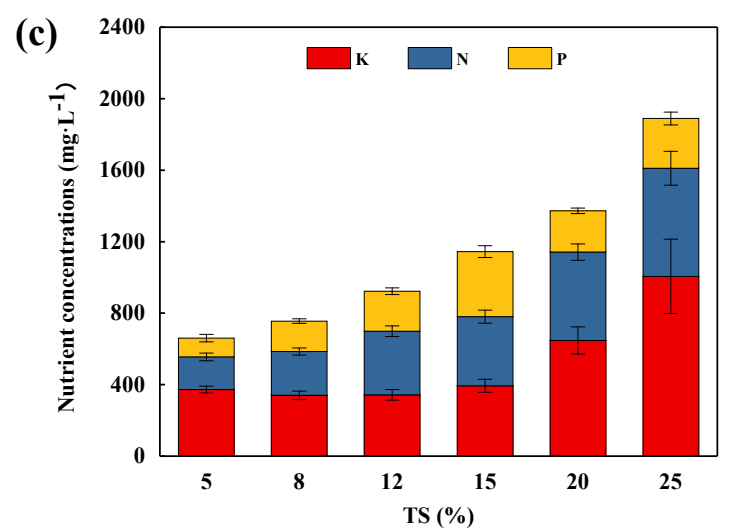

Fig. 4

681 

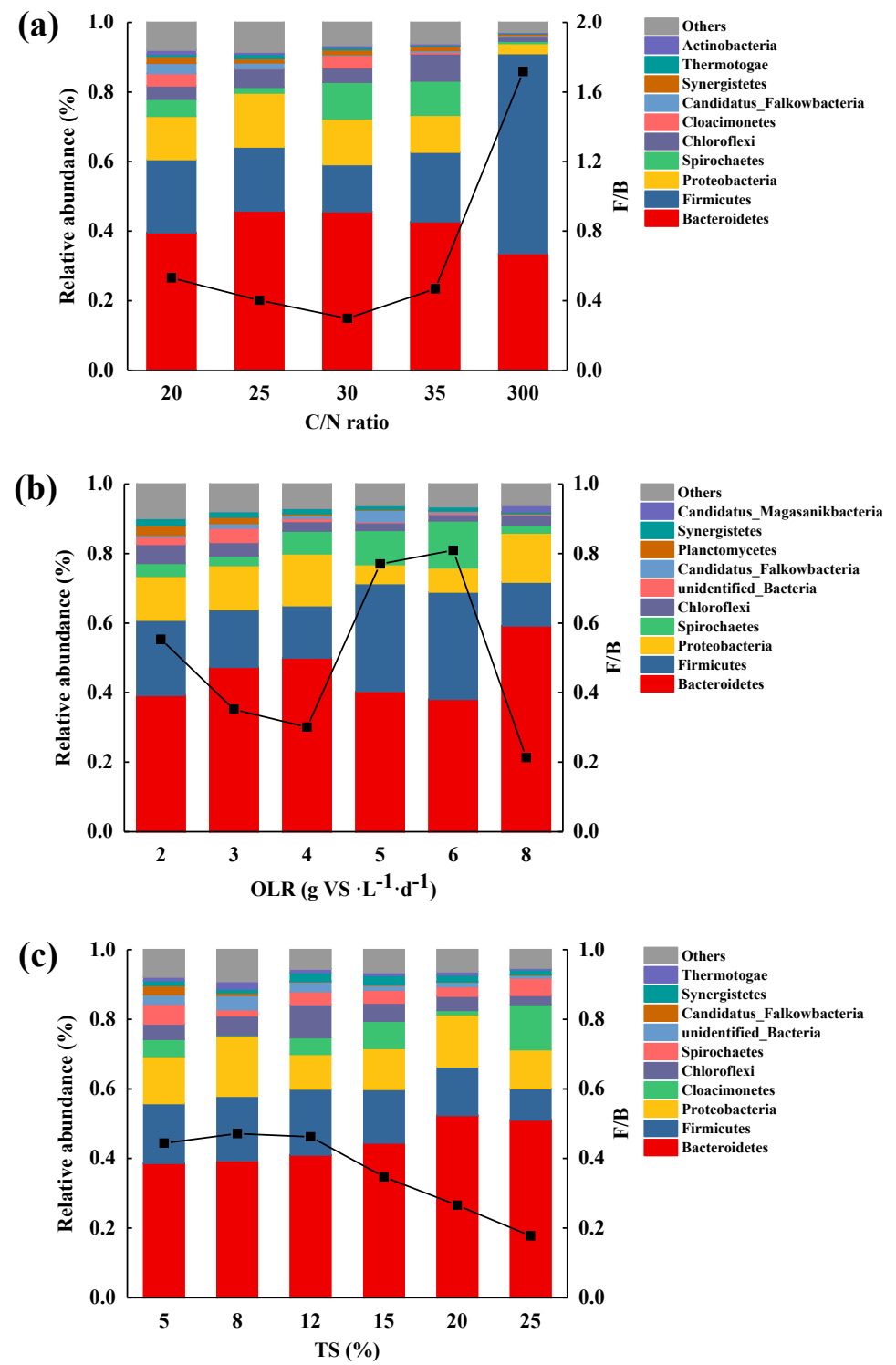

Fig. 5 
686
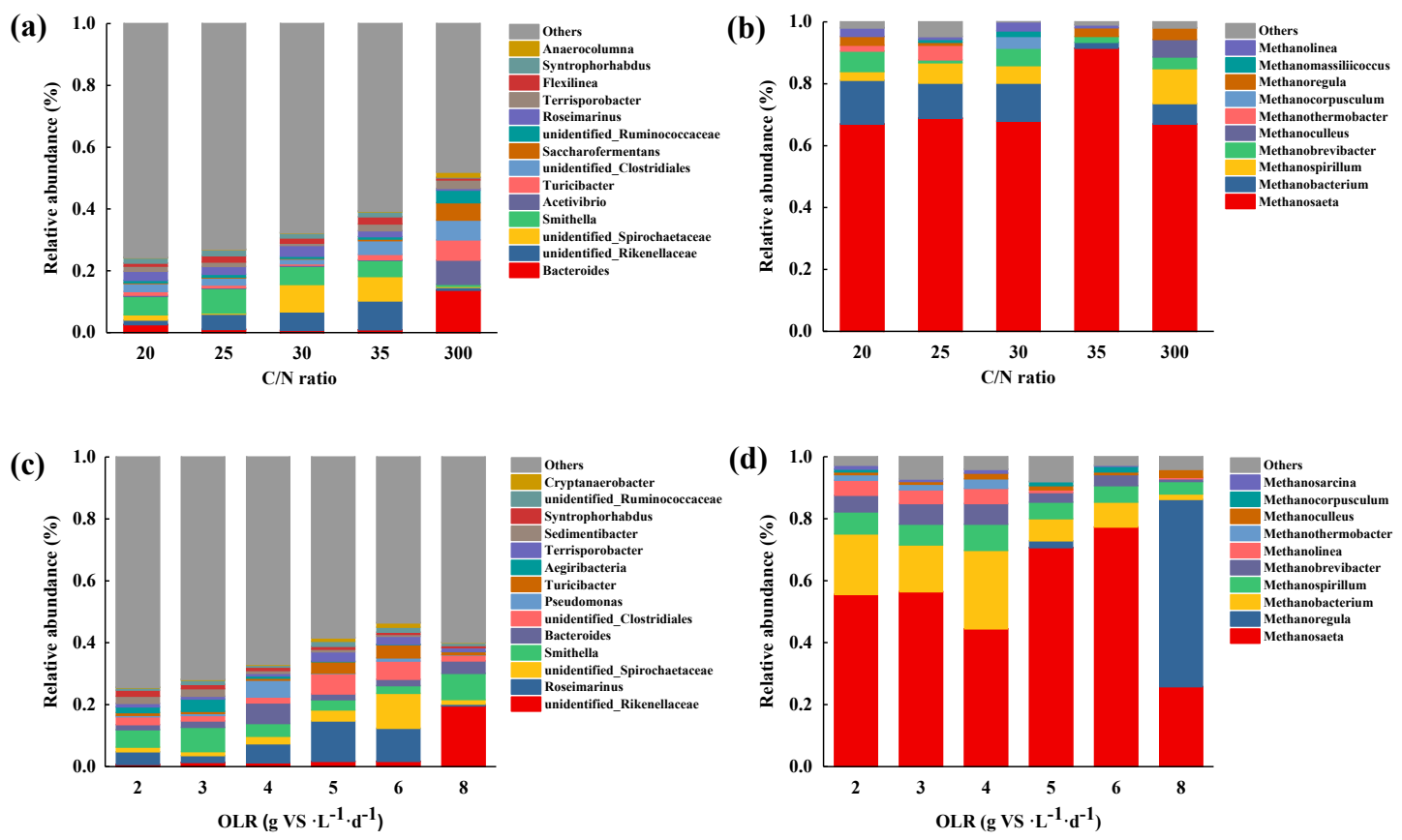

687
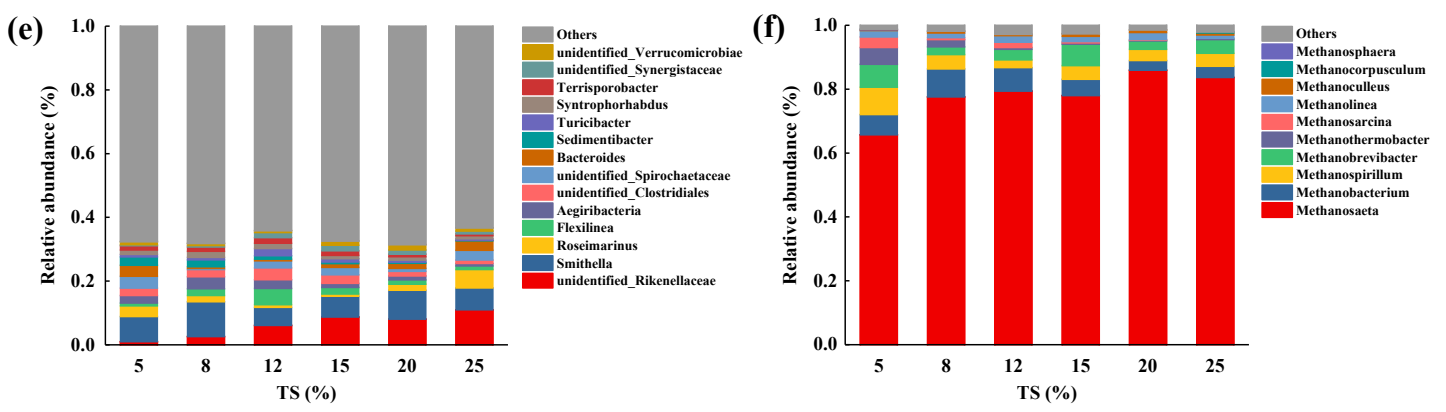

688

Fig. 6 


\begin{tabular}{|c|c|c|c|c|}
\hline Parameters & Pig manure & Corn straw & $\begin{array}{l}\text { Pretreated } \\
\text { corn straw }\end{array}$ & Inoculum \\
\hline${ }^{*} \mathrm{C}(\%)$ & $41.09 \pm 0.06$ & $50.12 \pm 1.84$ & $47.10 \pm 0.21$ & $31.21 \pm 0.94$ \\
\hline${ }^{*} \mathrm{~N}(\%)$ & $3.06 \pm 0.01$ & $0.22 \pm 0.01$ & $0.16 \pm 0.01$ & $3.40 \pm 0.13$ \\
\hline $\mathrm{C} / \mathrm{N}$ ratio & $13.45 \pm 0.02$ & $227.80 \pm 8.34$ & $294.38 \pm 5.6$ & $9.18 \pm 0.07$ \\
\hline TS ( $\%)$ & $30.07 \pm 0.87$ & $90.33 \pm 0.07$ & $99.02 \pm 0.07$ & $15.83 \pm 0.18$ \\
\hline VS (\%) & $81.06 \pm 0.64$ & $86.02 \pm 0.79$ & $86.09 \pm 0.83$ & $62.12 \pm 0.15$ \\
\hline
\end{tabular}

Note: "based on dry matter. 
Table 2 Design of operation parameters during anaerobic digestion

\begin{tabular}{|c|c|c|c|c|c|c|c|c|}
\hline & $\begin{array}{l}\mathrm{C} / \mathrm{N} \\
\text { ratio }\end{array}$ & "PM/CS & $\begin{array}{l}\mathrm{TS} \\
(\%)\end{array}$ & $\begin{array}{c}\text { OLR } \\
\left(\mathrm{g} \mathrm{VS} \cdot \mathrm{L}^{-1} \cdot \mathrm{d}^{-1}\right)\end{array}$ & $\begin{array}{l}\text { HTR } \\
\text { (day) }\end{array}$ & $\begin{array}{l}{ }^{\#} \mathrm{PM} \\
(\mathrm{g})\end{array}$ & $\begin{array}{l}{ }^{\sharp} \mathrm{CS} \\
(\mathrm{g})\end{array}$ & $\begin{array}{l}\text { Water } \\
(\mathrm{g})\end{array}$ \\
\hline \multirow{6}{*}{ CSTR I } & 13.45 & - & 5 & 2 & 20.31 & 65.64 & 0 & 328.21 \\
\hline & 20 & 2.19 & 5 & 2 & 20.55 & 44.36 & 6.15 & 338.73 \\
\hline & 25 & 1.22 & 5 & 2 & 20.74 & 35.05 & 8.77 & 341.87 \\
\hline & 30 & 0.84 & 5 & 2 & 20.87 & 28.75 & 10.54 & 344.00 \\
\hline & 35 & 0.63 & 5 & 2 & 20.97 & 24.19 & 11.82 & 345.54 \\
\hline & 300 & - & 5 & 2 & 21.50 & 0 & 18.79 & 353.3 \\
\hline \multirow{6}{*}{ CSTR II } & 25 & 1.22 & 5 & 2 & 20.74 & 35.05 & 8.77 & 341.87 \\
\hline & 25 & 1.22 & 5 & 3 & 13.83 & 52.58 & 13.15 & 512.80 \\
\hline & 25 & 1.22 & 5 & 4 & 10.37 & 70.11 & 17.54 & 683.74 \\
\hline & 25 & 1.22 & 5 & 5 & 8.30 & 87.63 & 21.92 & 854.67 \\
\hline & 25 & 1.22 & 5 & 6 & 6.91 & 105.16 & 26.31 & 1025.61 \\
\hline & 25 & 1.22 & 5 & 8 & 5.19 & 140.21 & 35.07 & 1367.48 \\
\hline \multirow{6}{*}{ CSTR III } & 25 & 1.22 & 5 & 2 & 20.73 & 35.35 & 8.77 & 341.87 \\
\hline & 25 & 1.22 & 8 & 2 & 33.19 & 35.35 & 8.77 & 196.94 \\
\hline & 25 & 1.22 & 12 & 2 & 49.78 & 35.35 & 8.77 & 116.59 \\
\hline & 25 & 1.22 & 15 & 2 & 62.22 & 35.35 & 8.77 & 84.45 \\
\hline & 25 & 1.22 & 20 & 2 & 82.96 & 35.35 & 8.77 & 52.31 \\
\hline & 25 & 1.22 & 25 & 2 & 103.69 & 35.35 & 8.77 & 33.03 \\
\hline
\end{tabular}

693

Note: "based on dry matter; ${ }^{\text {\# }}$ based on wet matter; PM means pig manure; CS means corn straw.

694 
Table 3 Bacterial community richness and diversity during anaerobic digestion process.

\begin{tabular}{|c|c|c|c|c|c|}
\hline Parameters & Taxonomy & Shannon & Simpson & Ace & Chao1 \\
\hline \multirow[t]{5}{*}{$\mathrm{C} / \mathrm{N}$ ratio } & 20 & 7.5944 & 0.9845 & 1778.3015 & 1704.7609 \\
\hline & 25 & 7.4119 & 0.9807 & 1933.1946 & 1960.6667 \\
\hline & 30 & 6.9850 & 0.9732 & 1760.1241 & 1763.5412 \\
\hline & 35 & 6.6482 & 0.9690 & 1791.9377 & 1761.3906 \\
\hline & 300 & 6.1742 & 0.9567 & 1178.7112 & 1162.2264 \\
\hline \multirow{6}{*}{$\begin{array}{l}\text { OLR } \\
\left(\mathrm{gVS} \cdot \mathrm{L}^{-1} \cdot \mathrm{d}^{-1}\right)\end{array}$} & 2 & 7.5278 & 0.9772 & 1426.2058 & 1499.1416 \\
\hline & 3 & 6.5463 & 0.9455 & 1310.1586 & 1318.3778 \\
\hline & 4 & 6.7986 & 0.9679 & 1386.2455 & 1413.9130 \\
\hline & 5 & 6.4734 & 0.9647 & 1090.7276 & 1117.8594 \\
\hline & 6 & 6.5194 & 0.9643 & 1094.5125 & 1106.7982 \\
\hline & 8 & 5.8310 & 0.9400 & 956.1223 & 958.2376 \\
\hline \multirow[t]{6}{*}{ TS (\%) } & 5 & 7.0539 & 0.9754 & 1179.3714 & 1207.1667 \\
\hline & 8 & 7.3329 & 0.9834 & 1332.5258 & 1316.8214 \\
\hline & 12 & 6.6695 & 0.9729 & 978.6194 & 991.3628 \\
\hline & 15 & 6.7691 & 0.9733 & 1096.8892 & 1103.1290 \\
\hline & 20 & 6.6742 & 0.9735 & 1006.0719 & 976.0880 \\
\hline & 25 & 6.2359 & 0.9658 & 802.9063 & 842.2340 \\
\hline
\end{tabular}

696 